\title{
Incremental Burden on Quality of Life and Health Care Expenditures in Adults with Diabetes Complications: MEPS 2013-2015
}

\author{
Manasi S. Suryavanshi, MPH and Yi Yang, MD, PhD ${ }^{1,2}$ \\ 'Department of Pharmacy Administration, The University of Mississippi School of Pharmacy, Oxford, MS, USA; ${ }^{2}$ Center for Pharmaceutical Marketing \\ and Management, The University of Mississippi School of Pharmacy, Oxford, MS, USA.
}

J Gen Intern Med 34(6):812-4

DOI: $10.1007 / \mathrm{s} 11606-019-04827-9$

(c) Society of General Internal Medicine 2019

\section{INTRODUCTION}

The prevalence of diabetes in adults aged $\geq 18$ years has increased from 13.0 million in 1998 to 23.0 million in $2015,1,2$ and is expected to reach 35.9 million (14.0\%) by 2030 in the USA. ${ }^{3}$ The annual cost of diabetes was reported to be $\$ 245$ billion in 2012 , including $\$ 176$ billion in direct medical cost and $\$ 69$ billion in reduced productivity. ${ }^{4}$ Elevated blood sugar over a prolonged period of time can lead to many complications. ${ }^{4}$ As the prevalence of diabetes continues to increase, diabetes complications will continue to be a public health concern. ${ }^{3}$ Therefore, in this study, we estimated the treated prevalence of diabetes complications, evaluated the impact of diabetes complications on health-related quality of life (HRQOL), and quantified the incremental cost of diabetes complications using a large nationally representative sample of non-institutionalized adults with diabetes in the USA.

\section{METHODS}

This is a retrospective cross-sectional study using pooled data from the 2013-2015 Medical Expenditure Panel Survey (MEPS). Adults aged $\geq 18$ years with diabetes were identified using the Clinical Classification Codes (CCC). HRQOL was measured using the Short Form 12-Item Health Status Survey version 2 (SF-12v2) in MEPS. ${ }^{5}$ The 8 domains, the physical component summary (PCS), and mental component summary (MCS) scores of SF-12v2 were linearly transformed to a scale with a mean of 50 and standard deviation (SD) of 10 using norm-based scoring. ${ }^{5}$ Direct medical costs for adults with diabetes were obtained from MEPS individual event-level files and all costs were reported in 2015 US dollars.

A poster presentation was made at the International Society for Pharmacoeconomics and Outcomes Research (ISPOR) 23rd Annual Meeting May 19-23, 2018, in Baltimore, MD.

Published online March 19, 2019
The "treated prevalence" of diabetes complications was reported per 100 adults with diabetes. Multivariable linear regressions were conducted to assess the impact of diabetes complications on HRQOL. A priori difference of $0.3 \mathrm{SD}$ in HRQOL scores was considered clinically meaningful. ${ }^{6}$ Based on modified Park test and Pregibon link test, generalized linear models with gamma distribution and log link were used to quantify the incremental costs associated with diabetes complications. To control for confounding, individual sociodemographic and access to care characteristics were included in the analysis. MEPS sampling design variables were applied in all analyses to account for MEPS complex design and non-response. To account for pooling of data from multiple years, we adjusted the sampling weight variable by dividing it by the number of years of data being pooled. The sum of these adjusted weights represents the average annual population size and average annual expenditure over the pooled period. MEPS data used for this study is de-identified and publicly available; therefore, a review by the institutional review board was waived.

\section{RESULTS}

We identified 7098 adults with diabetes (weighted estimate, 21.1 million); the estimated annual treated prevalence of diabetes complications was 1498 (weighted estimate, 4.7 million). Compared with adult diabetes patients with complications, those without complications were more likely to be 35-64 years of age $(84.7 \%)$, female $(81.3 \%)$, Hispanic $(82.5 \%)$, married $(79.1 \%)$, employed $(88.2 \%)$, and privately insured $(80.0 \%)$.

The adjusted mean HRQOL domain, PCS, and MCS scores for diabetes patients with complications were significantly lower than those without complications (Table 1). The negative impact of diabetes complications was also clinically meaningful in adjusted mean scores of PCS (4.7 points), general health (5.1 points), physical functioning (4.6 points), role-physical (4.0 points), and bodily pain (3.0 points). The adjusted cost analyses show that diabetes complications were associated with significantly higher total direct medical costs $(\beta, 0.8 ; 95 \% \mathrm{CI}, 0.6-0.9 ; P<.0001)$; the average annual direct medical costs for diabetes patients with complications were $\$ 8955.1(P<0.001)$ higher than the average costs for those without complications (Table 2). 
Table 1 SF-12v2 Norm-Based Scores of Adults with Diabetes Without Complication Versus Diabetes with Complication for the Standard Form Scales and Summary Measures

\begin{tabular}{|c|c|c|c|c|}
\hline \multirow[t]{3}{*}{ HRQOL Scale } & \multicolumn{2}{|c|}{ Unadjusted mean scores } & \multicolumn{2}{|c|}{ Adjusted mean scores* } \\
\hline & \multirow{2}{*}{$\begin{array}{l}\begin{array}{l}\text { Diabetes without } \\
\text { complications } \\
(N=5600)\end{array} \\
\text { Mean (SE) }\end{array}$} & \multirow{2}{*}{$\begin{array}{l}\text { Diabetes with } \\
\text { complications } \\
(N=1498) \\
\text { Mean (SE) }\end{array}$} & \multirow{2}{*}{$\begin{array}{l}\begin{array}{l}\text { Diabetes without } \\
\text { complications } \\
(N=5600)\end{array} \\
\text { Mean (SE) }\end{array}$} & \multirow{2}{*}{$\begin{array}{l}\begin{array}{l}\text { Diabetes with } \\
\text { complications } \\
(N=1498)\end{array} \\
\text { Mean (SE) }\end{array}$} \\
\hline & & & & \\
\hline Physical functioning (PF) & $44.7(0.3)$ & $37.6(0.6)^{\ddagger}$ & $48.6(0.8)$ & $44.0(1.0)^{\ddagger}$ \\
\hline Role-physical (RP) & $45.1(0.3)$ & $38.5(0.5)^{*}$ & $46.9(0.6)$ & $42.9(0.7)^{*}$ \\
\hline Bodily pain (BP) & $44.5(0.3)$ & $39.5(0.6)^{*}$ & $46.6(0.7)$ & $43.6(0.8)^{*}$ \\
\hline General health (GH) & $42.9(0.2)$ & $37.2(0.5)^{\ddagger}$ & $43.8(0.8)$ & $38.7(0.9)^{*}$ \\
\hline Vitality (VT) & $49.3(0.2)$ & $45.4(0.4)$ & $51.9(0.7)$ & $49.1(0.8)^{\ddagger}$ \\
\hline Social functioning (SF) & $47.6(0.3)$ & $44.0(0.6)^{*}$ & $49.1(0.8)$ & $46.5(0.9)$ \\
\hline Role-emotional (RE) & $46.4(0.3)$ & $42.2(0.6)^{\ddagger}$ & $46.6(0.8)$ & $44.0(0.9)^{*}$ \\
\hline Mental health (MH) & $50.1(0.2)$ & $48.1(0.5)^{\dagger}$ & $51.0(0.8)$ & $48.9(0.9)^{\ddagger}$ \\
\hline $\begin{array}{l}\text { Physical component summary } \\
\text { (PCS) }\end{array}$ & $43.3(0.3)$ & $36.1(0.5)^{*}$ & $46.2(0.6)$ & $41.5(0.8)^{*}$ \\
\hline $\begin{array}{l}\text { Mental component summary } \\
\text { (MCS) }\end{array}$ & $50.2(0.2)$ & $48.6(0.5)^{\dagger}$ & $50.4(0.6)$ & $48.9(0.7)^{\dagger}$ \\
\hline
\end{tabular}

*Score comparisons adjusted for individual sociodemographic (age, gender, racelethnicity, body mass index [BMI], marital status) and access to care (employment status, household income, education, place of residence, and health insurance status) characteristics

$\leftarrow P<0.01$

$\not P<0.0001$

\section{DISCUSSION}

In this study, we found that diabetes complications had statistically significant and clinically meaningful negative impact on PCS, MCS, and all 8 domain scores of HRQOL, and are associated with significantly higher annual total direct medical costs. However, the results of this study should be interpreted in light of certain limitations. First, the reported prevalence of diabetes complications was treated prevalence which does not include any undiagnosed, untreated, and unreported conditions. Second, results of this study cannot be generalized to adults institutionalized at hospice, nursing home, and longterm care facilities. Additionally, we were unable to ascertain information on disease severity and duration which may bias the study results.

Author Contribution. M.S.S. researched data, conducted data analyses and interpretation, wrote, and edited the report. Y.Y. researched data, contributed to data interpretation, and edited the report. The final draft for submission was approved by all authors.

Table 2 Unadjusted and Adjusted Average Annual Direct Medical Costs in Adults with Diabetes Without Complications as Compared with Diabetes with Complications, Medical Expenditure Panel Survey 2013-2015

\begin{tabular}{|c|c|c|c|c|c|c|}
\hline \multirow[t]{3}{*}{ Health care cost $(\$)^{*}$} & \multicolumn{4}{|c|}{ Unadjusted average annual direct medical cost } & \multicolumn{2}{|c|}{$\begin{array}{l}\text { Adjusted average annual } \\
\text { direct medical cost }{ }^{\dagger}\end{array}$} \\
\hline & $\begin{array}{l}\text { Diabetes without } \\
\text { complications }(N=5600)\end{array}$ & $\begin{array}{l}\text { Diabetes with } \\
\text { complications }(N=1498)\end{array}$ & Cost difference & $P$ value & Cost difference & $P$ value \\
\hline & Mean \$, (SE) & Mean \$, (SE) & Mean \$, (SE) & & Mean \$, (SE) & \\
\hline Total direct medical & 9236.8 (478.6) & $21,690.0(1185.7)$ & $12,453.0(1114.3)$ & $<0.0001$ & $8955.1(831.8)$ & $<0.001$ \\
\hline Prescription drug & $3958.6(378.5)$ & $5966.4(273.1)$ & $2007.8(440.0)$ & $<0.0001$ & $1961.0(251.9)$ & $<0.001$ \\
\hline Emergency care & $276.3(21.7)$ & $558.2(49.5)$ & $281.9(54.8)$ & $<0.0001$ & $239.0(45.9)$ & $<0.001$ \\
\hline Inpatient & 1957.8 (195.0) & $7146.9(629.2)$ & $5189.2(623.5)$ & $<0.0001$ & $3433.1(487.5)$ & $<0.001$ \\
\hline Outpatient & $734.6(86.1)$ & $1378.1(271.1)$ & $643.5(280.6)$ & 0.023 & $482.2(139.3)$ & 0.001 \\
\hline Office-based visit & $1862.7(64.2)$ & $4728.4(484.8)$ & $2865.8(492.2)$ & $<0.0001$ & $2072.0(307.8)$ & $<0.001$ \\
\hline Other medical & $139.4(11.3)$ & $316.1(43.6)$ & $176.6(46.0)$ & 0.001 & $110.0(27.0)$ & $<0.001$ \\
\hline Home health & 307.5 (38.9) & $1595.8(243.8)$ & $1288.4(242.8)$ & $<0.0001$ & $571.5(169.2)$ & 0.001 \\
\hline
\end{tabular}

SE, standard error

*Expenditures adjusted for inflation with the CPI to reflect 2015 dollars

†Costs adjusted for individual sociodemographic (age, gender, racelethnicity, body mass index [BMI], marital status) and access to care (employment status, household income, education, place of residence, and health insurance status) characteristics

$\neq$ Total direct medical cost does not include costs incurred by patients in hospice, nursing home, or long-term care facilities 
Corresponding Author: Yi Yang, MD, PhD; Department of Pharmacy Administration, The University of Mississippi School of Pharmacy, Oxford, MS, USA (e-mail: yiyang@olemiss.edu).

\section{Compliance with Ethical Standards:}

Conflict of Interest: The authors declare that they do not have a conflict of interest.

\section{REFERENCES}

1. Centers for Disease Control and Prevention. National Diabetes Statistics Report, Estimates of Diabetes and Its Burden in the United States. Atlanta, GA: Centers for Disease Control and Prevention, U.S. Dept of Health and Human Services; 2017. https://www.cdc.gov/diabetes/pdfs/data/statistics/national-diabetes-statistics-report.pdf. Accessed December 1, 2018
2. Mokdad AH, Ford ES, Bowman BA, et al. Diabetes trends in the U.S.: 1990-1998. Diabetes Care. 2000;23(9):1278-1283.

3. Shaw JE, Sicree RA, Zimmet PZ. Global estimates of the prevalence of diabetes for 2010 and 2030. Diabetes Res Clin Pract. 2010;87(1):4-14. doi:https://doi.org/10.1016/j.diabres.2009.10.007

4. American Diabetes Association. Economic Costs of Diabetes in the U.S. in 2012. Diabetes Care. 2013;36(4):1033-1046. doi:https://doi.org/10. $2337 / \mathrm{dc} 12-2625$

5. Ware JE Jr, Kosinski M, Turner-Bowker DM, Gandek B User's Manual for the SF-12v2® Health Survey With a Supplement Documenting SF-12® Health Survey. Lincoln, RI: QualityMetric Incorporated; 2002.

6. Hays RD, Woolley JM. The Concept of Clinically Meaningful Difference in Health-Related Quality of Life Research: How Meaningful is it? PharmacoEconomics. 2000;18(5):419-423. doi:https://doi.org/10.2165/ 00019053-200018050-00001

Publisher's Note: Springer Nature remains neutral with regard to jurisdictional claims in published maps and institutional affiliations. 